\title{
OBSERVATIONS AND SIMULATIONS OF EQUINOCTIAL ASYMMETRY DURING LOW AND HIGH SOLAR ACTIVITIES
}

Olusegun Jonah, Eurico de Paula and Alam Kherani, National Institute for Space Research (INPE)

Copyright 2013, SBGf - Sociedade Brasileira de Geofísica

This paper was prepared for presentation during the $13^{\text {th }}$ International Congress of the Brazilian Geophysical Society held in Rio de Janeiro, Brazil, August 26-29, 2013.

Contents of this paper were reviewed by the Technical Committee of the $13^{\text {th }}$ International Congress of the Brazilian Geophysical Society and do not necessarily represent any position of the SBGf, its officers or members. Electronic reproduction or storage of any part of this paper for commercial purposes without the written consent of the Brazilian Geophysical Society is prohibited.

\section{Abstract}

Employing a dual frequency GPS receiver and using the SAMI2 ionospheric model at the equatorial stations (São Luís(salu) and Arequipa(areq)) and low-latitude stations (Cachoeira Paulista(chpi) and Porto Alegre(poal)), the measurement of the ionospheric total electron content (TEC) have been estimated for March and September equinoxes months during an extremely low solar activity of 2009 and an extremely high solar activity of 2001. The seasonal behavior of the ionosphere have been investigated for several decades but the differences of the ionosphere between the March and September equinoxes are still an open question. The analysis reveals that during low and high solar activities, the equinoctial asymmetry in the ionospheic plasma density is a phenomenon of both the low-latitude and equatorial region and occurs during both solar activities. The SAMI2 model was used to investigate the observed GPS TEC behavior and its reveals that, besides the important effects of the meridional wind and of the electric field effect (ExB drift), the thermospheric temperature and $\mathrm{O} / \mathrm{N} 2$ also plays an important role in the forming of the observed equinoctial asymmetry particularly around the magnetic equator in the ionosphere.

\section{Introduction}

Over the past decades, the studies of the ionospheric variation has been geared toward the seasonal and semiannual variations (Balan et al., 1994; Batista et al., 2004; Adbu et al., 2007, de Paula et al., 2008) as well as summer-to-winter and solstice-to-equinox differences (e.g., Mendillo et al., 2005; Rishbeth et al., 2000) using the peak electron density (NmF2), critical frequency of F2 layer (foF2) and Total electron content (TEC) data. However, no clear distinction has be made between the two equinoctial difference (Jee et al., 2004; Codrescu et al., 1999). Essex (1977) pointed out that at several station the TEC value in March-April are usually larger than the TEC values in September-October equinoxes. Bailey et al. (2000) reported an equinoctial difference in the topside $\mathrm{Ne}$ and Liu et al. (2010) pointed out that the equinoctial asymmetry in the ionospheric plasma density during low solar activity is mainly a low-latitude phenomenon.
The aim of the paper is to report using both simulation and observational evidence, the equinoctial asymmetry between March and September of both 2009 and 2001 solar activities and to point out the liable mechanisms responsible for this differences.

\section{Method}

\section{TEC measurement using Nagoya model}

The Absolute TEC (ATEC) used in the work was estimated from the Nagoya model by making use of the following principal equations (Otsuka et al., 2002).

The slant TEC at a point is mapped to the vertical TEC (VTEC) at that point and it is given by:

$T^{i}(t)=S\left(\varepsilon^{i}(t)\right) V^{i}(t)$,

where $\varepsilon^{i}=\varepsilon^{i}(t)$ is the elevation angle of GPS satellite,

$S=\left(\varepsilon^{i}\right)$ is the slant factor (mapping function) given by

$\frac{\tau_{i}}{\tau_{o}}$, and $\tau_{i}=$ length of ray path between 300 and 550

$\mathrm{km}$ altitude while $\tau_{o}$ is equal to the ionospheric thickness of $250 \mathrm{~km}$ for zenith path.

In order to eliminate errors, which increase relative to the slant factor, the cutoff elevation angle was fixed at $30^{\circ}$.

The absolute TEC can therefore be obtained by equation:

$I^{i}(t)=S\left(\varepsilon^{i}(t)\right) \cdot V^{i}(t)+B^{i}$

where $B^{i}$ is the instrumental biases of both the receiver and the satellite.

The $B^{i}$ was calculated by using the least square fitting method as shown by the following equation:

$$
E=\sum_{i}^{N_{s}} \sum_{k}^{N_{i}} W_{k}^{i}\left[\frac{\overline{I_{k}}}{\overline{S\left(\varepsilon_{k}^{i}\right)}}-\left(\overline{V_{k}}+\left(\frac{1}{\overline{S\left(\varepsilon_{k}^{i}\right)}}\right) B^{i}\right)\right]^{2} \quad W_{k}^{i}=\frac{1}{\overline{S\left(\varepsilon_{k}^{i}\right)}}
$$

where $W_{k}^{i}$ is the weighting function. Equating the equation to zero and taking the partial derivative of $E$ with respect to $\overline{V_{k}}$ and $B^{i}$, the $\left(\overline{V_{k}}\right.$ and $\left.B^{i}\right)$ can be solved to reduce error of hourly TEC average caused by assumption of thin shell model, partial uniformity of the hourly TEC average and setting $W_{k}^{i}$ as inverse of slant factor. 


\section{Observational \& simulated equinoctial asymmetry during low and high solar activities 2}

\section{TEC estimation using Simulation}

SAMI2 (Some another ionospheric model) is a physicsbased model of the ionosphere. It models the plasma and chemical evolution of seven ion species $\left(\mathrm{H}^{+}, \mathrm{He}^{+}, \mathrm{N}^{+}, \mathrm{O}^{+}\right.$, $\mathrm{N}_{2}^{+}, \mathrm{NO}^{+}$and $\mathrm{O}_{2}^{+}$) (Huba et al., 2000). in the altitude range mentioned of $90-20,000 \mathrm{~km}$. The neutral composition and temperature are specified using the empirical NRLMSISE00 model and the neutral winds using the HWM07 model. The dynamics of the SAMI2 model enable us to incorporate many parameters and consequently to simulate the effect of these parameters on the TEC.

\section{Results}

\section{The equinoctial asymmetry in the daily variation of} TEC

The TEC around equinox during both low and high solar activity is represented in Figure 1. The figure shows clearly the asymmetry between TEC values of March and September and how it varies as a function of local time, longitude (Areq and Salu) and latitude (Salu, Chpi, and Poal). Larger TEC values were observed in March for 2001 and 2009. Generally, large difference were observed during afternoon and evening time at the lowlatitude region compared to equatorial region. The F10.7 during 2009 does not vary much (from 69.2 in Mar to 70.5 in Sep) but there was reasonable variation of F10.7 in 2001 (from 177.7 in Mar to 233.8 in Sep). However, good correlation was found between TEC and F10.7 during both period (result not show here) which clarifies that solar flux could not be the principal reason for the equinoctial asymmetry during these periods.
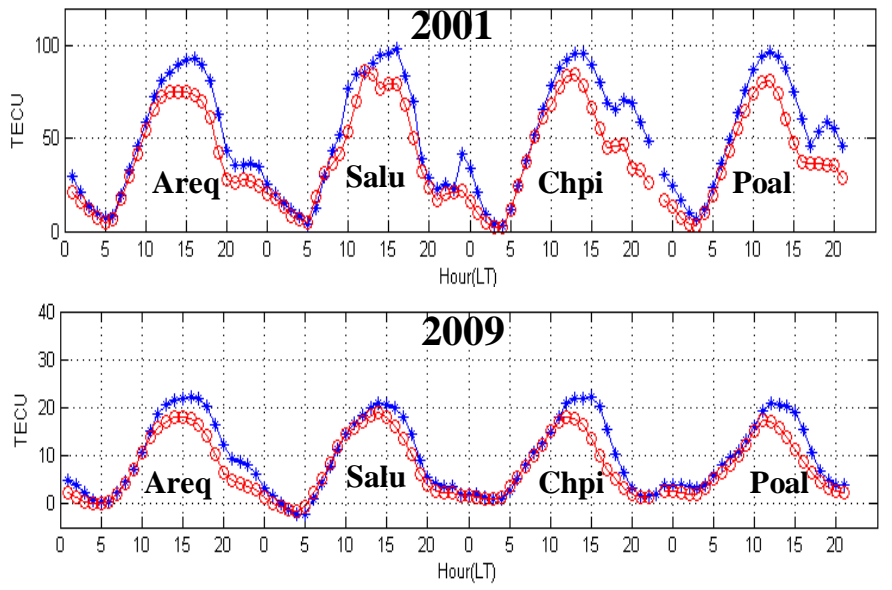

Figure 1: Diurnal TEC variation for March and September Equinoxes for 2001, (left panel) and 2009 (right panel). The red plots represent September equinox and the blue plots represent March equinox.

To investigate the possible causes for the equinoctial asymmetry between March and September, We employ the SAMI2 model with inclusion of the transport due to the electric field and meridional wind. The model results (Figure 2) show a good qualitative agreement with the observation as observed in the TEC during both afternoon and evening time. This would suggests that the electrodynamics processes was dominant over the chemical composition of the ionosphere during March equinoxes period.
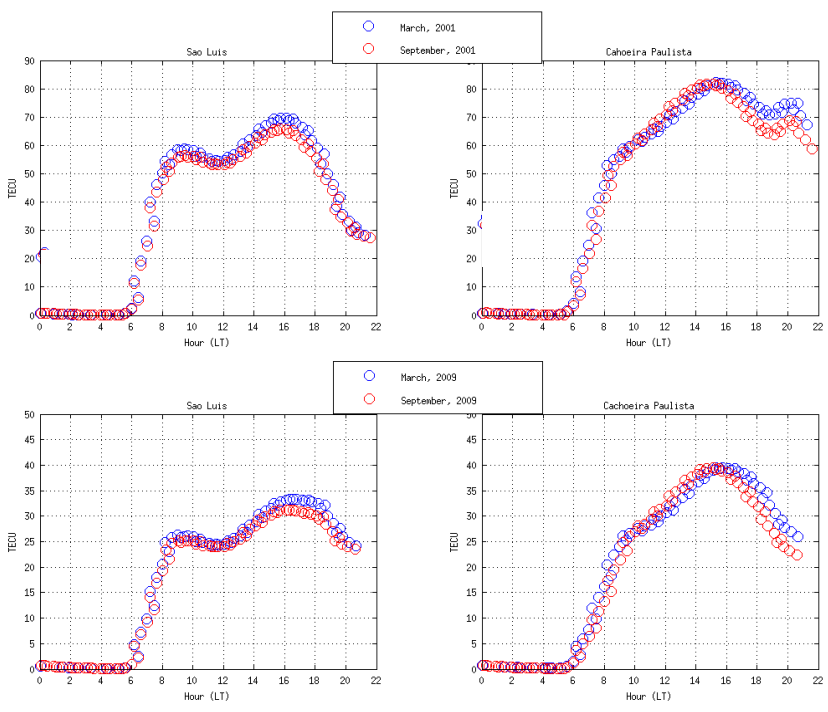

Figure 2: Diurnal TEC variation using SAMI2 model for March and September Equinoxes for 2001, (top panel) and 2009 (lower panel). The red circles represent September equinox and the blue circles represent March equinox.

The equinoctial asymmetry in the latitudinal variation of TEC

To observe the latitudinal behavior between March and September equinoxes, data for 2001 was not used since the statistic was poor due to lack of many receivers stations during this period. Therefore only 2009 low solar activity data were analyzed latitudinally. Figure 3 shows mean TEC along the magnetic dip latitude of $\pm 20^{\circ}$ traced along the magnetic field line within the geographic longitudinal range of $-52^{\circ}$ to $-60^{\circ}$ determined using the International Geomagnetic Reference Field (IGRF) model at 1400 hour local time during March equinox (blue line) and September equinox (red line). A close observation from the figure shows that latitudinal distribution of TEC during 2009 presents asymmetry around the low latitude and about the magnetic equator for both March and September. The March equinox shows larger TEC values than September equinox. The inter-hemisphere pattern also shows slight asymmetry. It can also be observed that the trough for both months are shifted away from $0^{\circ}$ (magnetic equator) towards the southern hemisphere. This could be a combined effect of interhemispheric wind and large separation between the geographic and geomagnetic equator along $60^{\circ} \mathrm{W}$. The wind at this large separation could be the cause of TEC trough shift from the magnetic equator. 


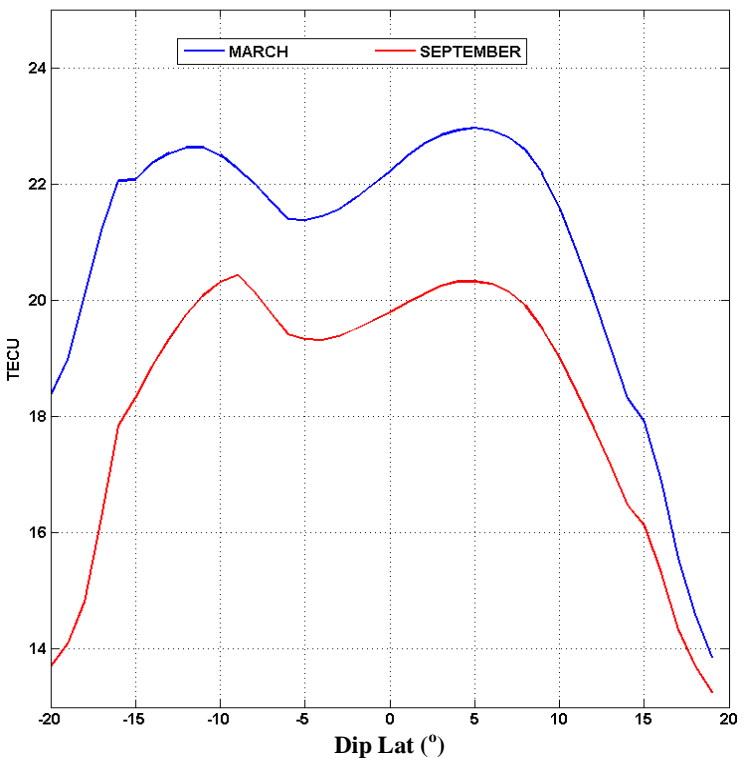

Figure 4 - Latitudinal distribution of TEC for March and September Equinoxes, at 1400LT for 2009.

The investigation of Liu et al. (2010) pointed out that the equinoctial asymmetry in the ionospheric plasma density during low solar activity is mainly a low-latitude phenomenon. Our results for both observation and simulation show that ionospheric plasma density could also be observed at the magnetic equator as illustrated by the São Luís station (Figure 1). The mechanism responsible for this could not be from electric field because high electric field at the magnetic equator transport plasma through the fountain effect to low latitudes. Therefore electric field could not be responsible for the relative larger TEC observed at the equator.

To investigate the possible causes for the equinoctial asymmetry in the latitudinal distribution of TEC, we use the SAMI2 model. The result is shown in Figure $4(\mathrm{~A})$. March TEC values exhibiting the effect of wind and photoionization and electric field illustrates larger hemispheric asymmetry and larger TEC value than September. We can also see that the wind effect is more prominent in September than in March. In order to infer the role of ambient atmospheric and photoionization conditions which could also contribute to the TEC asymmetry, we plot $\mathrm{O} / \mathrm{N} 2$ ratio and neutral temperature in Panels (B) and (C) of Figure 4. It is evident from this results that $\mathrm{O} / \mathrm{N} 2$ and temperature are larger during March than during September. The larger O/N2 implies less recombination which could leads to more TEC as found during March. Also, the larger temperature implies more photoionizations that could lead to more production of ions and electrons in March equinox compared to September.

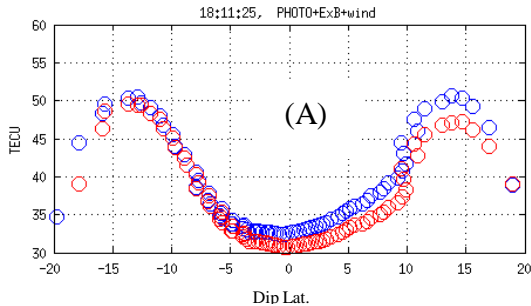

18:11:25, РнОТО
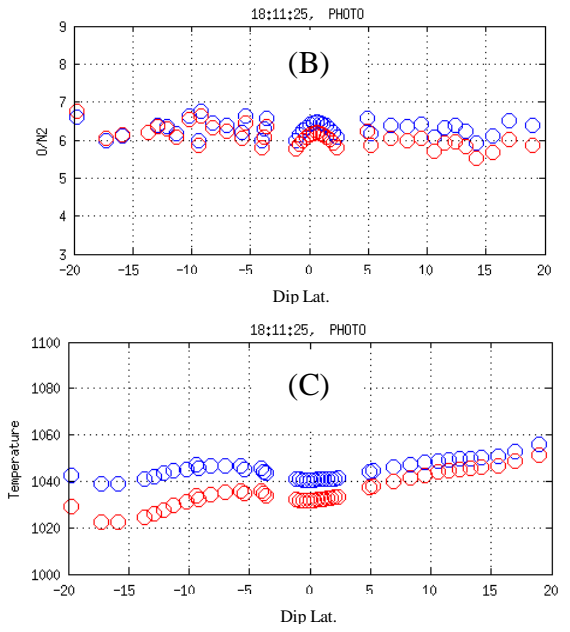

Figure 4 - Latitudinal TEC variation from typical SAMI2 model. Panel $A$, represents TEC of photoionization, $E \times B$ and Electric field, and wind, $B$, represents temperature of the ions and $C$, is the ratio of n/NO for hnth Marrh (hlıe) and Sentemher (red)

\section{Conclusions}

Using GPS-TEC observational data and the SAMI2 model, we have pointed out the liable factors responsible for TEC asymmetry between March and September equinoxes. Our result indicated that besides the electric field and wind responsible for larger TEC values during March and interhemispheric differences between March and September during both 2009 and 2001 solar activities at equatorial and low latitude region, temperature and composition of $\mathrm{O} / \mathrm{N} 2$ ratio are larger in March than September could be the factor responsible for the asymmetry at equatorial region during both solar activities.

\section{Acknowledgments}

The authors wish to express their gratitude to Dr. Otsuka of the Solar-Terrestrial Environment Laboratory Nagoya University, Toyokawa, Japan for the TEC model and Dr. Huba of Naval Research Laboratory (NRL) for the SAMI2 model.

\section{References}

ABDU, M. A.; BRUM, C.G.M.; BATISTA, I.S.; SOBRAL, J.H.A.; DE PAULA, E.R.; SOUZA, J.R. Solar flux effects on equatorial ionization anomaly and total electron 


\section{Observational \& simulated equinoctial asymmetry during low and high solar activities 4}

content over Brazil: observational results versus IRI representations. Journal of Advances in Space Research v. 42 p. $617-625,2007$.

BALAN, N.; BAILEY G. J. AND JAYACHANDRAN B., Ionospheric evidence for a non-linear relationship between the solar EUV and 10.7-cm fluxes during an intense solar cycle, Planet. Space Sci., v. 41, p. 141-145, 1993.

BATISTA, I.S. AND ABDU, M.A., Ionospheric variability at Brazilian low and equatorial latitudes comparison between observations and IRI model. Advances in Space Research v. 34 p. 1894-1894, 2004.

BAILEY, G. J., SU Y. Z., AND OYAMA K.-I. Yearly variations in the low-latitude topside ionosphere, Ann. Geophys., 18, 789-798. (2000),

CODRESCU, M. V.; PALO S. E.; ZHANG X.; FULLER-

ROWELL T. J. AND POPPE C. TEC climatology derived from TOPEX/POSEIDON measurements, J. Atmos. Sol. Terr. Phys., 61, 281 - 298, doi:10.1016/S13646826(98)00132-1, 1999.

DE PAULA, E. R., MUELLA, M. T. A. H. KHERANI, E. A. KINTNER, P. M. BATISTA, I. S. KANTOR, I. J. REZENDE, L. F. C. AND MITCHELL, C. N. A linkage between the $L$ band amplitude scintillations and the steepest TEC gradients at the boundaries of the equatorial ionization anomaly crests, Eos Trans. AGU, 89(53), Fall Meet. Suppl., Abstract G41A06172008,

Essex, E. A. Equinoctial variations in the total electron content of the ionosphere at Northern and Southern Hemisphere stations, J. Atmos. Terr. Phys., 39, 645-650, (1977),

HUBA, J. D.; JOYCE G.; FEDDER J. A., SAMI2 is another model of the ionosphere (SAMI2): A new lowlatitude ionosphere model, Journal of Geophysical Research, 105(A10), v. 23, p. 035-23,053, 2000.

JEE, G.; SCHUNK R. W.; SCHERLIESS L., Analysis of TEC data from the TOPEX/Poseidon mission, Journal of Geophysical Research, doi:10.1029/2003JA010058, 2004.

LIU, H.-L.; WANG W.; RICHMOND A. D.; AND ROBLE R. G. Iono- spheric variability due to planetary waves and tides for solar minimum conditions, Journal of Geophysical Research, doi:10.1029/2009JA015188, 2010.

MENDILLO, M., HUANG, C. PI, X. RISHBETH, H. AND MEIER R. The global ionospheric asymmetry in total electron content, J. Atmos. Sol. Terr. Phys., 67, 13771387, (2005),

OTSUKA, Y.; OGAWA, T.; SAITO, A.; TSUGAWA, T.; FUKAO, S.; MIYAZAKI; S. A new technique for mapping of total electron content using GPS network in Japan. Journal of Earth Planets Space, v. p. 54, 63-70, 2002.
RISHBETH, H.; MULLER -WODARG, I. C. F.; ZOU, L.; FULLER-ROWELL T. J.; MILLWARD G. H.; MOFFETT R. J.; IDENDEN D. W.; AYLWARD A. D. Annual and semiannual variations in the ionospheric F2-layer: II. Physical discussion, Ann. Geophys., v. 18, p. 945-956, 2000. 